\title{
Pathological tumor response to neoadjuvant chemotherapy using anthracycline and taxanes in patients with triple-negative breast cancer
}

\author{
KAORI SAKUMA ${ }^{1,4}$, MASAFUMI KUROSUMI ${ }^{1}$, HANAKO OBA ${ }^{1}$, YASUHITO KOBAYASHI ${ }^{1}$, \\ HIROYUKI TAKEI ${ }^{2}$, KENICHI INOUE ${ }^{3}$, TOSHIO TABEI ${ }^{3}$ and TETSUNARI OYAMA ${ }^{4}$ \\ ${ }^{1}$ Department of Pathology, and Divisions of ${ }^{2}$ Breast Surgery and ${ }^{3}$ Breast Oncology, Saitama Cancer Center, Saitama; \\ ${ }^{4}$ Department of Diagnostic Pathology, Gunma University Graduate School of Medicine, Gunma, Japan
}

Received October 25, 2010; Accepted January 17, 2011

DOI: $10.3892 / \mathrm{etm} .2011 .212$

\begin{abstract}
Although triple-negative breast cancer (TNBC) is associated with a poor prognosis, recent reports have indicated that a higher proportion of TNBC patients shows a pathological complete response (pCR) to neoadjuvant chemotherapy (NAC) than is the case for non-TNBC patients. The aim of this study was to identify markers that predict $\mathrm{pCR}$ to NAC in TNBC patients, and to clarify prognostic factors that affect the outcome of TNBC patients with residual disease (RD) after NAC. Among 44 TNBC patients who received anthracycline- and taxane-based combination NAC, we analyzed the relationship between pathological response and clinicopathological characteristics, including immunohistochemical parameters (cytokeratin 5/6, epidermal growth factor receptor, Ki-67, p53, breast cancer susceptibility protein 1 and topoisomerase II $\alpha$ ). We also assessed the prognostic impact on patients with RD by analyzing the correlation between disease-free survival (DFS) and clinicopathological parameters. Sixteen patients (36\%) achieved a pCR and logrank test showed that these patients had a significantly more favorable outcome than patients with RD (DFS, $\mathrm{P}=0.00184$; overall survival, $\mathrm{P}=0.0080$ ). Among the clinicopathological parameters examined, none was correlated with pathological response, with the exception of p53. Patients with immunohistochemical overexpression of p53 more frequently achieved a $\mathrm{pCR}$ than those without $\mathrm{p} 53$ overexpression $(\mathrm{P}=0.0484)$. In the patients with RD, the Cox proportional hazards model showed that the presence of lymphovascular invasion was significantly associated with shorter DFS (hazard ratio, 13.333; 95\% CI 1.587-111.111; $\mathrm{P}=0.0171)$. p53 overexpression may be a key predictor of a favorable response to NAC. Since patients with
\end{abstract}

Correspondence to: Dr Masafumi Kurosumi, Department of Pathology, Saitama Cancer Center, 818 Komuro, Ina-machi, Kitaadati-gun, Saitama 362-0806, Japan

E-mail: mkurosumi@cancer-c.pref.saitama.jp

Key words: triple-negative breast cancer, p53, neoadjuvant chemotherapy, pathological complete response, basal-like
RD, particularly those positive for lymphovascular invasion, had an extremely poor outcome, novel therapeutic approaches for these patients are warranted.

\section{Introduction}

Triple-negative breast cancer (TNBC) is a type of breast cancer that lacks expression of estrogen receptor (ER), progesterone receptor (PR) and human epidermal growth factor receptor 2 (HER2). This subtype accounts for $10-25 \%$ of all breast cancers (1-7) and is frequently observed in patients of African or Hispanic descent, whereas it is relatively uncommon among Asian patients $(4,6,8)$. TNBC is known to be associated with a poor prognosis $(3-5,7)$.

Recently, gene expression studies using DNA microarrays have identified several distinct breast cancer subtypes: two ER-positive subtypes (luminal A and B) and three ER-negative subtypes (HER2-positive, basal-like and normal breastlike) $(9,10)$. Among these subtypes, the basal-like subtype is clinically relevant since it shows a clinical course that is as aggressive as the HER2-positive subtype $(9,10)$. Most breast cancers of the basal-like subtype have been reported to be immunohistochemically positive for cytokeratin (CK) 5/6 and/or epidermal growth factor receptor (EGFR), but negative for ER and HER2 (11). It appears that the basal-like subtype constitutes $80 \%$ of TNBCs and is more aggressive than the non-basal-like subtype of TNBCs $(2,3)$.

Due to the lack of proper therapeutic targets, patients with TNBC usually do not benefit from appropriate therapy, such as hormone or HER2-targeted therapy. An increasing number of patients with TNBC, which are not always at an advanced stage, have been receiving neoadjuvant chemotherapy (NAC), and this has resulted in a higher rate of partial resection, rather than mastectomy. Several studies have reported that TNBC responds more frequently to NAC than non-TNBC, and consequently $20-30 \%$ of TNBC patients achieve a pathological complete response (pCR) $(1,8,12)$. Breast cancer patients who achieve a pCR to NAC generally have an excellent prognosis, while patients with residual disease (RD), whose invasive carcinoma cells do not disappear completely even after NAC, usually have a poor prognosis $(8,13)$. It seems 
that TNBC patients with RD after NAC have a considerably worse prognosis than non-TNBC patients with RD. Liedtke et al (1) reported that $68 \%$ of TNBC patients with $\mathrm{RD}$ after NAC survived for at least 3 years after surgery, in comparison to $88 \%$ of patients with non-TNBC. Collectively, TNBC includes NAC-sensitive and -resistant subgroups, which show a significant difference in outcome after NAC. Therefore, it is necessary to identify markers that distinguish these subgroups.

In the present study, we analyzed TNBC patients who received combination NAC with anthracycline and taxane at a single institution. Our main aim was to identify markers that could predict pCR to NAC by analyzing the correlation between clinicopathological parameters and pathological response. We also attempted to clarify prognostic factors that have a major influence on the outcome of TNBC patients with RD after NAC.

\section{Materials and methods}

Patients and tumor characteristics. This study included 44 TNBC patients with a median age of 52 years (range 36-70). These patients received anthracycline- and taxanebased combination chemotherapy prior to surgery at Saitama Cancer Center, Saitama, Japan, between July 2004 and July 2008. The characteristics of the patients and their tumors are listed in Table I. The mean follow-up period was 12 months (range 1-35). Patients at clinical stages II, III and IV were enrolled. The 1 patient with clinical stage IV disease had only ipsilateral subclavicular lymph node involvement. Clinical tumor size, lymph node status and TNM status were evaluated by clinical examination, mammography, breast ultrasonography and magnetic resonance imaging. The tumor subtype in 39 patients was invasive ductal carcinoma, not otherwise specified (NOS), and the tumors in the other 5 patients comprised 3 metaplastic carcinomas, 1 apocrine carcinoma and 1 invasive micropapillary carcinoma, respectively, on the basis of the WHO criteria (14). The histological grade of each tumor was assessed according to the criteria described by Elston and Ellis (15), and all of the tumors were judged as grade III.

Treatment. Thirty-three patients received 4 cycles of doxorubicin $\left(60 \mathrm{mg} / \mathrm{mm}^{2}\right)$ and cyclophosphamide $\left(600 \mathrm{mg} / \mathrm{mm}^{2}\right)$ followed by 4 cycles of docetaxel $\left(70 \mathrm{mg} / \mathrm{mm}^{2}\right)$. The treatment regimens in the other patients are described in Table I. After completion of NAC, 41 patients underwent breast-conserving therapy and the others underwent mastectomy. Postoperative radiotherapy was performed for the 41 patients who received breast-conserving therapy. Among the 10 patients whose tumors were diagnosed as having a positive surgical margin (tumor cells being observed within $5 \mathrm{~mm}$ from the surgical margin by histological examination), 2 underwent additional breast-conserving therapy and the others received additional booster radiotherapy.

Definition of triple-negative breast cancer. Expression of ER and PR was evaluated by immunohistochemistry. Tumors were interpreted as negative for ER and PR when $<10 \%$ of all tumor cells showed nuclear staining. HER2 was considered to
Table I. Patient and tumor characteristics.

\begin{tabular}{lc}
\hline Characteristics & No. \\
\hline Age range (median), in years & $36-70(52)$ \\
$\leq 40$ & 5 \\
$>40$ & 39 \\
Menopausal status & \\
Pre-menopausal & 21 \\
Menopausal & 23 \\
Clinical tumor size & \\
T1 & 3 \\
T2 & \\
T3 & 24 \\
T4 & 11 \\
\end{tabular}

Clinical lymph node status

No 8

N1 26

$\mathrm{N} 2$

5

N3

M1 (ipsilateral subclavicular lymph node)

Clinical TNM stage

IIA

IIB 15

IIIA 11

IIIB 4

IIIC 4

IV

Histology

Invasive ductal carcinoma, NOS 39

Metaplastic carcinoma 3

Apocrine carcinoma

Invasive micropapillary carcinoma

Regimens of neoadjuvant chemotherapy

4 cycles of $\mathrm{AC}\left(60^{\mathrm{a}}, 600^{\mathrm{a}}\right)$

and 4 cycles of $\mathrm{T}\left(70^{\mathrm{a}}\right)$

4 cycles of $\mathrm{AC}\left(60^{\mathrm{a}}, 600^{\mathrm{a}}\right)$

and 12 cycles of $P\left(80^{\mathrm{a}}\right)$

4 cycles of AP $\left(50^{\mathrm{a}}, 150^{\mathrm{a}}\right)$

and 4 cycles of $\mathrm{T}\left(70^{\mathrm{a}}\right)$

or 12 cycles of $\mathrm{P}\left(80^{\mathrm{a}}\right)$

4 cycles of EC $\left(75^{\mathrm{a}}, 600^{\mathrm{a}}\right)$

and 4 cycles of $\mathrm{T}\left(70^{\mathrm{a}}\right)$

or 12 cycles of $\mathrm{P}\left(80^{\mathrm{a}}\right)$

4 cycles of $\operatorname{CEF}\left(500^{\mathrm{a}}, 100^{\mathrm{a}}, 500^{\mathrm{a}}\right)$

and 4 cycles of $\mathrm{T}\left(70^{\mathrm{a}}\right)$

Type of surgery

Breast-conserving therapy

Mastectomy

aDose of neoadjuvant chemotherapy $\left(\mathrm{mg} / \mathrm{mm}^{2}\right)$. ${ }^{\mathrm{b}}$ Since the tumors of 2 patients markedly progressed in size even during neoadjuvant chemotherapy, 1 patient underwent breast-conserving therapy following 1 cycle of docetaxel and the other received 2 cycles of doxorubicin and cyclophosphamide additionally following 2 cycles of docetaxel. NOS, not otherwise specified; A, doxorubicin; C, cyclophosphamide; E, epirubicin; F, fluorouracil; T, docetaxel; P, paclitaxel. 
be negative when the HER 2 score was 0 or $1+$ by immunohistochemistry, or when the HER2/CEP17 gene copy ratio was $<1.8$ by FISH analysis in tumors, the HER2 score of which was $2+$. TNBCs were defined as ER-negative, PR-negative and HER2-negative breast cancers.

Assessment of pathological response and definition of pathological complete response. The response grade of each tumor was determined by at least three of the authors (K.S., H.O. and M.K.). The degree of pathological response to NAC was evaluated according to the response criteria of the Japanese Breast Cancer Society (16). pCR was defined as complete disappearance of invasive carcinoma cells in both the breast and axillary lymph nodes after NAC. Residual intraductal carcinoma was included in the pCR category (13).

Clinicopathological studies for prediction of pathological complete response to neoadjuvant chemotherapy. The relationships between pathological response and clinicopathological characteristics (age, menopausal status, clinical tumor size, lymph node status, TNM stage, histological classification, morphological features and immunohistochemical parameters) were analyzed in order to identify factors that are closely correlated with pCR to NAC. For the histological analysis, we focused our attention on the 39 invasive ductal carcinomas, since the other five tumor types are biologically distinct from conventional invasive ductal carcinomas. We examined the 39 pre-treatment core-needle biopsy specimens to detect markers that were significantly correlated with a good response to NAC. The morphological features evaluated were central necrosis, central fibrosis, lymphoid stroma and pushing margin. These features are frequently found in ER-negative breast carcinomas and basal-like-subtype breast carcinomas (overlapped with TNBC) $(17,18)$. The immunohistochemical parameters evaluated were CK5/6, EGFR, $\mathrm{Ki}-67$, p53, breast cancer susceptibility protein 1 (BRCA1) and topoisomerase II $\alpha$ (TOPO II $\alpha$ ). The methods used for immunohistochemistry were previously described (19). The clone designations, companies that supplied the primary antibodies and dilution factors used were: CK5/6 (D5/16B4; Dako Japan; 1:50), Ki-67 (MIB-1; Dako Japan; 1:50), p53 (DO7; Dako Japan; 1:100), BRCA1 (MS110; EMD Bioscience Calbiochem; 1:50) and TOPO II $\alpha$ (Ki-S1; Dako Japan; 1:100). EGFR was stained using an EGFRpharmDx kit (Dako Japan) in accordance with the manufacturer's instructions. Cases were interpreted as positive for CK5/6 and EGFR when any of the tumor cells had cytoplasmic and membranous staining, respectively. The basal-like subtype was defined as CK5/6and/or EGFR-positive among the TNBCs (11). The Ki-67 labeling index (LI) was defined as the ratio of MIB-1-stained tumor cells to all tumor cells counted, multiplied by 100 . To evaluate the Ki-67 LI, stained tumor cells were counted in at least three high-power fields that showed the highest positivity in each section. Since TNBC commonly shows a high Ki-67 LI, we used a Ki-67 LI of 50\% as a cut-off point to define each tumor as having a high or low Ki-67 LI; this value was almost equal to the mean index of TNBC observed at our institution. For the expression of p53, BRCA1 and TOPO II $\alpha$, nuclear staining cutoff values of 25 (12), 10 (20) and 25\% (2) of all tumor cells, respectively, were used to define positivity.
Clinicopathological studies for the prediction of outcome after neoadjuvant chemotherapy. For this analysis, from 28 TNBC patients with RD 1 patient with stage IV disease was excluded. Of the 27 patients with RD, the relationships between disease-free survival (DFS) and various clinicopathological characteristics were assessed to identify the factors related to outcome after NAC. We analyzed the surgical materials resected after NAC to obtain data on pathological parameters (tumor size, lymph node status, TNM status, grade of pathological response and lymphovascular invasion).

Statistical analysis. Fisher's exact test was conducted to analyze the associations between pathological response to NAC and clinicopathological characteristics. The KaplanMeier method was used to estimate the DFS and overall survival (OS) survivorship functions. Survival curves of the pCR and RD groups were compared using the log-rank test. The univariate Cox proportional hazards model was used to derive factors that were predictive of unfavorable DFS in patients with RD after NAC.

\section{Results}

Pathological response and survival analysis. No residual invasive carcinoma cells in the breast were confirmed histologically in 19 of the 44 patients (43\%) after NAC. Three of the 19 patients, however, had residual carcinoma cells in the resected lymph nodes. As a result, 16 of the 44 patients $(36 \%)$ achieved a pCR. All of the patients with pCR were alive and well during their follow-up periods (mean 17.5; range 1-35 months). On the other hand, 8 of the 28 patients (29\%) with RD relapsed during follow-up (mean 11; range 2-33 months) and died of breast cancer within 2 years after surgery. Log-rank test showed that patients with pCR had a significantly more favorable outcome than patients with RD (DFS, $\mathrm{P}=0.00184$; OS, $\mathrm{P}=0.0080$ ) (Fig. 1).

Factors predictive of a pathological response to neoadjuvant chemotherapy. Although the associations between pathological response to NAC and the clinicopathological characteristics (age, menopausal status, clinical tumor size, lymph node status, TNM stage and histological classification) were evaluated, none of the characteristics was significantly correlated with pathological response, as represented in Table II.

In the 39 invasive ductal carcinomas that were examined histologically, the only factor that was significantly associated with response to NAC was immunohistochemical overexpression of p53 (Table III; P=0.0484). The representative histology and immunohistochemistry for p53 of a tumor that disappeared in response to NAC are shown in Fig. 2. In addition, it was suggested that an absence of central necrosis was correlated with a higher $\mathrm{pCR}$ rate $(\mathrm{P}=0.0832)$. The $\mathrm{pCR}$ rate for basal-like subtype cancers, accounting for 34 of the 39 invasive ductal carcinomas $(87 \%)$, was similar to that for non-basal-like subtype cancers. Although overexpression of TOPO II $\alpha$ was observed in 27 of the 39 invasive ductal carcinomas $(69 \%)$, no significant correlation between overexpression and the rate of pathological response to NAC was observed. 

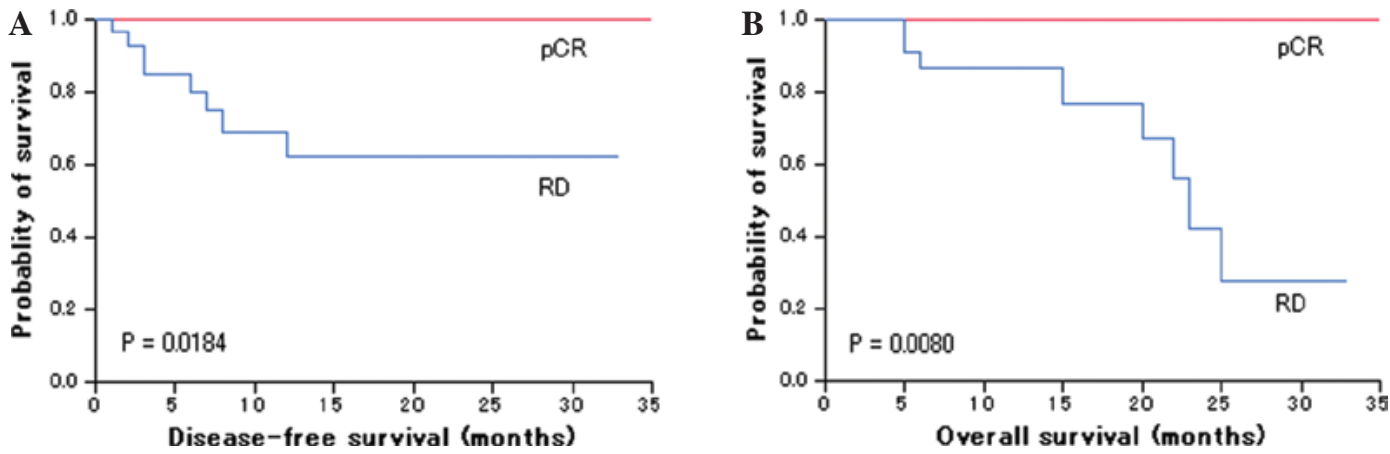

Figure 1. Disease-free survival (A) and overall survival (B) comparing patients who achieved a pathological complete response to those who had residual disease after neoadjuvant chemotherapy.

Table II. Correlations between pathological response and clinicopathological characteristics.

\begin{tabular}{|c|c|c|c|}
\hline Characteristics & pCR, no. $(\%)$ & RD, no. (\%) & P-value ${ }^{a}$ \\
\hline \multicolumn{4}{|l|}{ Age, in years } \\
\hline$\leq 40$ & $1(20)$ & $4(80)$ & \multirow[t]{2}{*}{0.6380} \\
\hline$>40$ & $15(38)$ & $24(62)$ & \\
\hline \multicolumn{4}{|l|}{ Menopausal status } \\
\hline Pre-menopausal & $7 \quad(33)$ & $14(67)$ & \multirow[t]{2}{*}{0.7606} \\
\hline Menopausal & $9 \quad(39)$ & $14(61)$ & \\
\hline \multicolumn{4}{|l|}{ Clinical tumor size } \\
\hline $\mathrm{T} 1, \mathrm{~T} 2$ & $9(33)$ & $18(67)$ & \multirow[t]{2}{*}{0.7495} \\
\hline $\mathrm{T} 3, \mathrm{~T} 4$ & $7 \quad(41)$ & $10(59)$ & \\
\hline \multicolumn{4}{|l|}{ Clinical lymph node status } \\
\hline Negative & $2(25)$ & $6(75)$ & \multirow[t]{2}{*}{0.6895} \\
\hline Positive & $14(39)$ & $22(61)$ & \\
\hline \multicolumn{4}{|l|}{ Clinical TNM stage } \\
\hline IIA, IIB & $9 \quad(38)$ & $15(63)$ & \multirow[t]{2}{*}{$>0.9999$} \\
\hline IIIA, IIIB, IIIC, IV & $7 \quad(35)$ & $13(65)$ & \\
\hline \multicolumn{4}{|l|}{ Histology } \\
\hline Invasive ductal carcinoma, NOS & $15 \quad(38)$ & $24(62)$ & \multirow[t]{4}{*}{$0.6380^{\mathrm{b}}$} \\
\hline Metaplastic carcinoma & $0 \quad(0)$ & $3(100)$ & \\
\hline Apocrine carcinoma & $1(100)$ & $0 \quad(0)$ & \\
\hline Invasive micropapillary carcinoma & $0 \quad(0)$ & $1(100)$ & \\
\hline
\end{tabular}

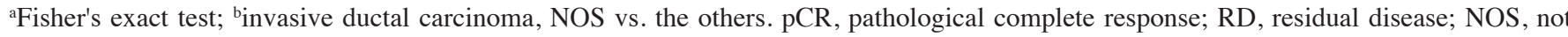
otherwise specified.

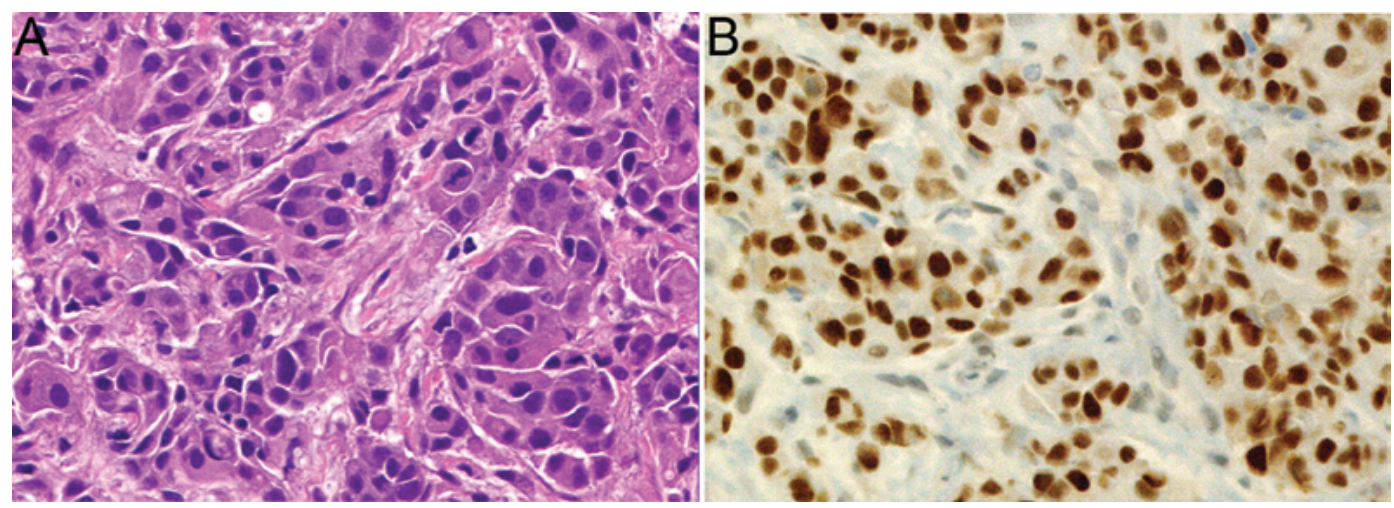

Figure 2. Representative tumor histology of a patient who achieved a pathological complete response. (A) Marked nuclear atypia and some mitoses are noted (H\&E staining). (B) Nuclear overexpression of p53 is apparent in nearly all of the tumor cells (immunohistochemistry for p53). 
Table III. Correlations between pathological response and histological features, including immunohistochemical parameters.

\begin{tabular}{|c|c|c|c|}
\hline Characteristics & pCR, no. $(\%)$ & RD, no. (\%) & P-value \\
\hline \multicolumn{4}{|l|}{ Central necrosis } \\
\hline Positive & $2(17)$ & $10(83)$ & \multirow[t]{2}{*}{0.0832} \\
\hline Negative & $13(48)$ & $14(52)$ & \\
\hline \multicolumn{4}{|l|}{ Central fibrosis } \\
\hline Positive & $3(30)$ & $7(70)$ & \multirow[t]{2}{*}{0.7110} \\
\hline Negative & $12(41)$ & 17 (59) & \\
\hline \multicolumn{4}{|c|}{ Lymphoid stroma } \\
\hline Positive & $3(60)$ & $2(40)$ & \multirow[t]{2}{*}{0.3541} \\
\hline Negative & $12(35)$ & $22(65)$ & \\
\hline \multicolumn{4}{|l|}{ Pushing margin } \\
\hline Positive & $11(35)$ & $20(65)$ & \multirow[t]{2}{*}{0.6857} \\
\hline Negative & $4(50)$ & $4(50)$ & \\
\hline \multicolumn{4}{|c|}{ Basal-like phenotype } \\
\hline Yes & $13(38)$ & $21(62)$ & \multirow[t]{2}{*}{$>0.9999$} \\
\hline No & $2(40)$ & $3(60)$ & \\
\hline \multicolumn{4}{|l|}{ Ki-67 LI } \\
\hline High LI & $11(39)$ & $17(61)$ & \multirow[t]{2}{*}{$>0.9999$} \\
\hline Low LI & $4(36)$ & $7(64)$ & \\
\hline \multicolumn{4}{|l|}{ p53 } \\
\hline Positive & $11(55)$ & $9(45)$ & \multirow[t]{2}{*}{0.0484} \\
\hline Negative & $4(21)$ & $15(79)$ & \\
\hline \multicolumn{4}{|l|}{ BRCA1 } \\
\hline Positive & $4(27)$ & $11(73)$ & \multirow[t]{2}{*}{0.3172} \\
\hline Negative & $11(46)$ & $13(54)$ & \\
\hline \multicolumn{4}{|l|}{ TOPO II $\alpha$} \\
\hline Positive & $11(41)$ & $16(59)$ & \multirow[t]{2}{*}{0.7342} \\
\hline Negative & $4(33)$ & $8(67)$ & \\
\hline
\end{tabular}

${ }^{a}$ Fisher's exact test. pCR, pathological complete response; RD, residual disease; LI, labeling index; BRCA1, breast cancer susceptibility protein 1 ; TOPO II $\alpha$, topoisomerase II $\alpha$.

Factors predictive of disease-free survival among the 27 patients with residual disease after neoadjuvant chemotherapy. Lymphovascular invasion was found to significantly correlate with shorter DFS (hazard ratio, 13.333; 95\% CI 1.587-111.111; $\mathrm{P}=0.0171)$, as shown in Table IV.

\section{Discussion}

In the present study we showed that p53 overexpression in the TNBCs examined was strongly correlated with increased susceptibility of the cancer to NAC. This finding is in line with data obtained from European TNBC patients who received NAC (21). Among previous analyses of breast cancers with various ER and HER2 statuses, some have shown that p53 abnormalities, including gene mutation, LOH or immunohistochemical overexpression, are significantly associated with resistance to anthracycline-based chemotherapy $(22,23)$, whereas others have not supported this conclusion (24-26). Although the relationship between p53 abnormality and sensitivity to NAC seems to be unproven among breast cancers as a whole, it is likely that immunohistochemical overexpression of p53 protein is a reliable indicator of a good response to NAC in TNBC. It has also been demonstrated that p53 overexpression or mutation is present more frequently in TNBC than in non-TNBC $(2,3,27)$. From a clinical viewpoint, this suggests that more TNBC patients than non-TNBC patients may achieve a pCR to NAC. However, as our study population was small, the results need to be validated in a larger number of TNBC patients.

Normal p53 protein induces G1 arrest and repairs damage to DNA, or causes apoptosis in cells with DNA damage. In the present study, TNBCs that were positive for p53 overexpression, many of which were considered to have lost their normal p53 function, showed a much better response to NAC than those that were negative, many of which would have normal p53 function. TNBC cells that have lost their p53 function appear to accumulate DNA damage, resulting in cell death during or after NAC. In other words, a lack of normal p53 function in TNBC cells appears to be one of the factors determining susceptibility to NAC. 
Table IV. Correlations between disease-free survival after surgery and clinicopathological characteristics in patients with residual disease.

\begin{tabular}{|c|c|c|c|c|c|}
\hline Characteristics & Total no. & Relapse no. (\%) & Hazard ratio & $95 \% \mathrm{CI}$ & P-value \\
\hline \multicolumn{6}{|l|}{ Age, in years } \\
\hline$\leq 40$ & 4 & $1(25)$ & 0.800 & $0.095-6.704$ & 0.8366 \\
\hline$>40$ & 23 & $6(26)$ & 1 & & \\
\hline \multicolumn{6}{|l|}{ Menopausal status } \\
\hline Pre-menopausal & 14 & $3(21)$ & 0.652 & $0.145-2.935$ & 0.5770 \\
\hline Menopausal & 13 & $4(31)$ & 1 & & \\
\hline \multicolumn{6}{|l|}{ Clinical tumor size ${ }^{\mathrm{b}}$} \\
\hline $\mathrm{T} 1, \mathrm{~T} 2$ & 18 & $5(28)$ & 1.371 & $0.265-7.087$ & 0.7066 \\
\hline $\mathrm{T} 3, \mathrm{~T} 4$ & 9 & $2(22)$ & 1 & & \\
\hline \multicolumn{6}{|l|}{ Pathological tumor size ${ }^{c}$} \\
\hline $\mathrm{T} 0, \mathrm{~T} 1, \mathrm{~T} 2$ & 24 & $5(21)$ & 0.316 & $0.061-1.637$ & 0.1698 \\
\hline $\mathrm{T} 3, \mathrm{~T} 4$ & 3 & $2(67)$ & 1 & & \\
\hline \multicolumn{6}{|l|}{ Clinical lymph node status ${ }^{\mathrm{b}}$} \\
\hline Positive & 21 & $6(29)$ & 1.541 & $0.185-12.821$ & 0.6898 \\
\hline Negative & 6 & $1(17)$ & 1 & & \\
\hline \multicolumn{6}{|l|}{ Pathological lymph node status ${ }^{c}$} \\
\hline Positive & 18 & $6(33)$ & 2.188 & $0.259-18.519$ & 0.4722 \\
\hline Negative & 9 & $1(11)$ & 1 & & \\
\hline \multicolumn{6}{|l|}{ Clinical TNM stage ${ }^{\mathrm{b}}$} \\
\hline IIA, IIB & 15 & $2(13)$ & 0.304 & $0.059-1.578$ & 0.1565 \\
\hline IIIA, IIIB, IIIC & 12 & $5(42)$ & 1 & & \\
\hline \multicolumn{6}{|l|}{ Pathological TNM stage ${ }^{c}$} \\
\hline I, IIA, IIB & 22 & $4(18)$ & 0.373 & $0.083-1.672$ & 0.1974 \\
\hline IIIA, IIIB, IIIC & 5 & $3(60)$ & 1 & & \\
\hline \multicolumn{6}{|l|}{ Histology } \\
\hline Invasive ductal carcinoma, NOS & 23 & $5(22)$ & 0.488 & $0.094-2.525$ & 0.3918 \\
\hline Others & 4 & $2(50)$ & 1 & & \\
\hline \multicolumn{6}{|l|}{ Grade of pathological response } \\
\hline $3^{\mathrm{d}}, 2 \mathrm{~b}, 2 \mathrm{a}$ & 7 & $2(29)$ & 1.183 & $0.229-6.135$ & 0.8405 \\
\hline $1 \mathrm{~b}, 1 \mathrm{a}$ & 20 & $5(25)$ & 1 & & \\
\hline \multicolumn{6}{|l|}{ Lymphovascular invasion after NAC } \\
\hline Positive & 10 & $6(60)$ & 13.333 & $1.587-111.111$ & 0.0171 \\
\hline Negative & 17 & $1(6)$ & 1 & & \\
\hline
\end{tabular}

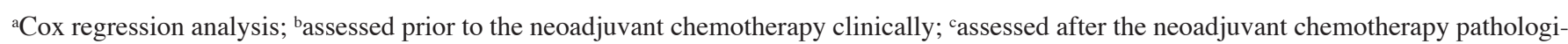
cally; ${ }^{\mathrm{d}}$ carcinoma cells remaining only in the lymph node. NOS, not otherwise specified; NAC, neoadjuvant chemotherapy.

In the present study, all of the TNBC patients with pCR were alive and well during their follow-up periods. On the other hand, 8 of the 28 patients with RD after NAC, whose tumors showed various degrees of response to NAC, relapsed within 2 years after surgery and died of the disease. TNBC patients with RD after NAC, which constitute $70-80 \%$ of TNBC cases, are likely to relapse soon after completion of their therapy. Therefore, the clinical outcome for TNBC as a whole remains poor, irrespective of the high $\mathrm{pCR}$ rate $(1,8,12)$. We found that the presence of lymphovascular invasion in the residual tumor tissues after NAC was significantly associated with a poorer outcome in patients with RD. Nogi et al (28) reported that EGFR-positive TNBC patients had a worse outcome after NAC compared to patients with EGFR-negative tumors. In our study, none of the immunohistochemical markers examined, including CK5/6, EGFR, Ki-67, p53, BRCA1 and TOPO II $\alpha$, were positively correlated with outcome in patients with RD (data not shown). Since little is known about the prognostic factors of TNBC patients with RD after NAC, the factors strongly influencing outcome in such patients remain to be clarified.

TOPO II $\alpha$ is known to be a target molecule of anthracyclines. Approximately $40 \%$ of HER2-positive breast cancers have been shown to have a TOP2A gene amplification (29), as the gene is located next to the HER2 gene on chromosome 17q12-q21. Although very few HER2-negative breast cancers have a TOP2A gene amplification, previous studies have indicated that $80-90 \%$ of TNBCs are immunohistochemically 
positive for TOPO II $\alpha$ protein $(2,30)$. The finding that $69 \%$ of the TNBCs we examined demonstrated TOPO II $\alpha$ protein overexpression is compatible with previous data. Although it is reported that TOPO II $\alpha$-positive breast cancers, i.e., those showing a gene amplification and/or protein overexpression, are susceptible to anthracycline $(29,31,32)$, we did not observe a prominent correlation between TOPO II $\alpha$ protein expression and pathological response to NAC. On the other hand, TOPO II $\alpha$ protein expression is apparently associated with the growth activity of breast cancer cells $(33,34)$. In our study, the expression of TOPO II $\alpha$ protein was significantly correlated with the Ki-67 LI (data not shown) of the tumor cells. Thus, high positivity for TOPO II $\alpha$ in TNBC seems to reflect the high proliferative activity of the tumor cells.

In conclusion, immunohistochemical overexpression of p53 in TNBC cells has been shown to be strikingly correlated with a pCR; p53 overexpression may thus be a marker of a more favorable response to anthracycline- and taxane-based NAC. TNBC patients with residual disease after NAC, particularly those with lymphovascular invasion, often relapsed and died of the cancer. There is an urgent need to develop effective therapy for TNBCs that are resistant to anthracycline- and taxane-based NAC.

\section{References}

1. Liedtke C, Mazouni C, Hess KR, et al: Response to neoadjuvant therapy and long-term survival in patients with triple-negative breast cancer. J Clin Oncol 26: 1275-1281, 2008.

2. Tan DS, Marchió C, Jones RL, Savage K, Smith IE, Dowsett M and Reis-Filho JS: Triple negative breast cancer: molecular profiling and prognostic impact in adjuvant anthracycline-treated patients. Breast Cancer Res Treat 111: 27-44, 2008.

3. Rakha EA, El-Sayed ME, Green AR, Lee AH, Robertson JF and Ellis IO: Prognostic markers in triple-negative breast cancer. Cancer 109: 25-32, 2007.

4. Bauer KR, Brown M, Cress RD, Parise CA and Caggiano V: Descriptive analysis of estrogen receptor (ER)-negative, progesterone receptor (PR)-negative, and HER2-negative invasive breast cancer, the so-called triple-negative phenotype: a population-based study from the California Cancer Registry. Cancer 109: 1721-1728, 2007.

5. Haffty BG, Yang Q, Reiss M, Kearney T, Higgins SA, Weidhaas J, Harris L, Hait W and Toppmeyer D: Locoregional relapse and distant metastasis in conservatively managed triple negative early-stage breast cancer. J Clin Oncol 24: 5652-5657, 2006.

6. Carey LA, Perou CM, Livasy CA, et al: Race, breast cancer subtypes, and survival in the Carolina Breast Cancer Study. JAMA 295: 2492-2502, 2006.

7. Dent R, Trudeau M, Pritchard KI, Hanna WM, Kahn HK, Sawka CA, Lickley LA, Rawlinson E, Sun P and Narod SA: Triple-negative breast cancer: clinical features and patterns of recurrence. Clin Cancer Res 13: 4429-4434, 2007.

8. Carey LA, Dees EC, Sawyer L, Gatti L, Moore DT, Collichio F, Ollila DW, Sartor CI, Graham ML and Perou CM: The triple negative paradox: primary tumor chemosensitivity of breast cancer subtypes. Clin Cancer Res 13: 2329-2334, 2007.

9. Sørlie T, Perou CM, Tibshirani R, et al: Gene expression patterns of breast carcinomas distinguish tumor subclasses with clinical implications. Proc Natl Acad Sci USA 98: 10869-10874, 2001.

10. Sorlie T, Tibshirani R, Parker J, et al: Repeated observation of breast tumor subtypes in independent gene expression data sets. Proc Natl Acad Sci USA 100: 8418-8423, 2003.

11. Nielsen TO, Hsu FD, Jensen K, et al: Immunohistochemical and clinical characterization of the basal-like subtype of invasive breast carcinoma. Clin Cancer Res 10: 5367-5374, 2004.

12. Keam B, Im SA, Kim HJ, et al: Prognostic impact of clinicopathologic parameters in stage II/III breast cancer treated with neoadjuvant docetaxel and doxorubicin chemotherapy: paradoxical features of the triple negative breast cancer. BMC Cancer 7: 203, 2007.
13. Mazouni C, Peintinger F, Wan-Kau S, Andre F, Gonzalez Angulo AM, Symmans WF, Meric-Bernstam F, Valero V, Hortobagyi GN and Pusztai L: Residual ductal carcinoma in situ in patients with complete eradication of invasive breast cancer after neoadjuvant chemotherapy does not adversely affect patient outcome. J Clin Oncol 25: 2650-2655, 2007.

14. Tavassoli FA and Devilee P: World Health Organization Classification of Tumours: Pathology and Genetics of Tumours of the Breast and Female Genital Organs. IARC Press, Lyon, 2003.

15. Elston CW and Ellis IO: Pathological prognostic factors in breast cancer. I. The value of histological grade in breast cancer: experience from a large study with long-term follow-up. Histopathology 19: 403-410, 1991.

16. Kurosumi M: Significance and problems in evaluations of pathological responses to neoadjuvant therapy for breast cancer. Breast Cancer 13: 254-259, 2006.

17. Putti TC, El-Rehim DM, Rakha EA, Paish CE, Lee AH, Pinder SE and Ellis IO: Estrogen receptor-negative breast carcinomas: a review of morphology and immunophenotypical analysis. Mod Pathol 18: 26-35, 2005.

18. Livasy CA, Karaca G, Nanda R, Tretiakova MS, Olopade OI, Moore DT and Perou CM: Phenotypic evaluation of the basallike subtype of invasive breast carcinoma. Mod Pathol 19: 264-271, 2006.

19. Kono S, Kurosumi M, Simooka H, Kawanowa K, Ninomiya J, Takei H, Suemasu K and Kuroda Y: Immunohistochemical study of the relationship between Ki-67 labeling index of proliferating cells of gynecomastia, histological phase and duration of disease. Pathol Int 56: 655-658, 2006.

20. Yang Q, Sakurai T, Mori I, Yoshimura G, Nakamura M, Nakamura Y, Suzuma T, Tamaki T, Umemura T and Kakudo K: Prognostic significance of BRCA1 expression in Japanese sporadic breast carcinomas. Cancer 92: 54-60, 2001.

21. Bidard FC, Matthieu MC, Chollet P, Raoefils I, Abrial C, Dômont J, Spielmann M, Delaloge S, André F and Penault Llorca F: p53 status and efficacy of primary anthracyclines/alkylating agentbased regimen according to breast cancer molecular classes. Ann Oncol 19: 1261-1265, 2008

22. Geisler S, Lønning PE, Aas T, Johnsen H, Fluge O, Haugen DF, Lillehaug JR, Akslen LA and Børresen-Dale AL: Influence of TP53 gene alterations and c-erbB-2 expression on the response to treatment with doxorubicin in locally advanced breast cancer. Cancer Res 61: 2505-2512, 2001

23. Aas T, Børresen AL, Geisler S, Smith-Sørensen B, Johnsen H, Varhaug JE, Akslen LA and Lønning PE: Specific P53 mutations are associated with de novo resistance to doxorubicin in breast cancer patients. Nat Med 2: 811-814, 1996.

24. Mieog JS, van der Hage JA, van de Vijuer MJ and van de Velde CJ; Cooperating Investigators of the EORTC: Tumour response to preoperative anthracycline-based chemotherapy in operable breast cancer: the predictive role of p53 expression. Eur J Cancer 42: 1369-1379, 2006

25. Colleoni M, Orvieto E, Nolé F, et al: Prediction of response to primary chemotherapy for operable breast cancer. Eur J Cancer 35: 574-579, 1999.

26. Bertheau P, Turpin E, Rickman DS, Espié M, de Reyniès A, Feugeas JP, Plassa LF, Soliman H, Varna M, de Roquancourt A, Lehmann-Che J, Beuzard Y, Marty M, Misset JL, Janin A and de Thé H: Exquisite sensitivity of TP53 mutant and basal breast cancers to a dose-dense epirubicin-cyclophosphamide regimen. PLoS Med 4: e90, 2007.

27. Umemura S, Takekoshi S, Suzuki Y, Saitoh Y, Tokuda Y and Osamura RY: Estrogen receptor-negative and human epidermal growth factor receptor 2-negative breast cancer tissue have the highest Ki-67 labeling index and EGFR expression: gene amplification does not contribute to EGFR expression. Oncol Rep 14: 337-343, 2005.

28. Nogi H, Kobayashi T, Suzuki M, Tabei I, Kawase K, Toriumi Y, Fukushima $\mathrm{H}$ and Uchida K: EGFR as paradoxical predictor of chemosensitivity and outcome among triple-negative breast cancer. Oncol Rep 21: 413-417, 2009.

29. Tanner M,Isola J, Wiklund T,Erikstein B,Kellokumpu-Lehtinen P, Malmström P, Wilking N, Nilsson J and Bergh J: Topoisomerase IIalpha gene amplification predicts favorable treatment response to tailored and dose-escalated anthracycline-based adjuvant chemotherapy in HER-2/neu-amplified breast cancer: Scandinavian Breast Group Trial 9401. J Clin Oncol 24: 2428-2436, 2006. 
30. Arriola E, Rodriguez-Pinilla SM, Lambros MB, Jones RL, James M, Savage K, Smith IE, Dowsett M and Reis-Filho JS: Topoisomerase II alpha amplification may predict benefit from adjuvant anthracyclines in HER2 positive early breast cancer. Breast Cancer Res Treat 106: 181-189, 2007.

31. MacGrogan G, Rudolph P, Mascarel Id I, et al: DNA topoisomerase IIalpha expression and the response to primary chemotherapy in breast cancer. Br J Cancer 89: 666-671, 2003.

32. Järvinen TA, Tanner M, Rantanen V, Bärlund M, Borg A, Grénman S and Isola J: Amplification and deletion of topoisomerase IIalpha associate with ErbB-2 amplification and affect sensitivity to topoisomerase II inhibitor doxorubicin in breast cancer. Am J Pathol 156: 839-847, 2000.
33. Lynch BJ, Guinee DG Jr and Holden JA: Human DNA topoisomerase II-alpha: a new marker of cell proliferation in invasive breast cancer. Hum Pathol 28: 1180-1188, 1997.

34. Järvinen TA, Kononen J, Pelto-Huikko M and Isola J: Expression of topoisomerase IIalpha is associated with rapid cell proliferation, aneuploidy, and c-erbB2 overexpression in breast cancer. Am J Pathol 148: 2073-2082, 1996. 